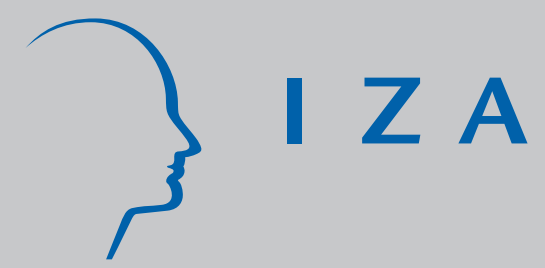

IZA DP No. 8055

Knowing that You Matter, Matters!

The Interplay of Meaning, Monetary Incentives, and

Worker Recognition

Michael Kosfeld

Susanne Neckermann

Xiaolan Yang

March 2014 


\title{
Knowing that You Matter, Matters! The Interplay of Meaning, Monetary Incentives, and Worker Recognition
}

\author{
Michael Kosfeld \\ Goethe University Frankfurt \\ and IZA \\ Susanne Neckermann \\ Erasmus University Rotterdam \\ Xiaolan Yang \\ Zhejiang University Hangzhou
}
Discussion Paper No. 8055
March 2014

\author{
IZA \\ P.O. Box 7240 \\ 53072 Bonn \\ Germany \\ Phone: +49-228-3894-0 \\ Fax: +49-228-3894-180 \\ E-mail: iza@iza.org
}

\begin{abstract}
Any opinions expressed here are those of the author(s) and not those of IZA. Research published in this series may include views on policy, but the institute itself takes no institutional policy positions. The IZA research network is committed to the IZA Guiding Principles of Research Integrity.

The Institute for the Study of Labor (IZA) in Bonn is a local and virtual international research center and a place of communication between science, politics and business. IZA is an independent nonprofit organization supported by Deutsche Post Foundation. The center is associated with the University of Bonn and offers a stimulating research environment through its international network, workshops and conferences, data service, project support, research visits and doctoral program. IZA engages in (i) original and internationally competitive research in all fields of labor economics, (ii) development of policy concepts, and (iii) dissemination of research results and concepts to the interested public.
\end{abstract}

IZA Discussion Papers often represent preliminary work and are circulated to encourage discussion. Citation of such a paper should account for its provisional character. A revised version may be available directly from the author. 


\section{ABSTRACT \\ Knowing that You Matter, Matters! The Interplay of Meaning, Monetary Incentives, and Worker Recognition*}

We manipulate workers' perceived meaning of a job in a field experiment. Half of the workers are informed that their job is important, the other half are told that their job is of no relevance. Results show that workers exert more effort when meaning is high, corroborating previous findings on the relationship between meaning and work effort. We then compare the effect of meaning to the effect of monetary incentives and of worker recognition via symbolic awards. We also look at interaction effects. While meaning outperforms monetary incentives, the latter have a robust positive effect on performance that is independent of meaning. In contrast, meaning and recognition have largely similar effects but interact negatively. Our results are in line with image-reward theory (Bénabou and Tirole 2006) and suggest that meaning and worker recognition operate via the same channel, namely image seeking.

\section{JEL Classification: $\quad$ C93, J33, M12, M52}

Keywords: meaning, monetary incentives, worker recognition, field experiment

Corresponding author:

Michael Kosfeld

Chair of Organization and Management

Goethe University Frankfurt

Grüneburgplatz 1

60323 Frankfurt/Main

Germany

E-mail: kosfeld@econ.uni-frankfurt.de

\footnotetext{
* Financial support from the DFG-ANR project "Understanding organisations - The complex interplay of incentives and identity" (FR 2822/1-1) is gratefully acknowledged.
} 


\section{Introduction}

Many people care about their job besides the income the job generates. Important motivations include the pure enjoyment somebody feels when performing the tasks a job comprises, the impact the job has on outcomes the individual cares about, the status and prestige a job conveys, or the social identity individuals share with other members in the organization. In recent years, a large literature in psychology and economics has documented and analyzed a number of non-pecuniary work motives both empirically and theoretically. The results suggest that employers have powerful instruments besides monetary compensation at their disposal to motivate and reward employee effort. ${ }^{1}$

One important factor that has received relatively little attention in the literature is the meaning, or meaningfulness, of a job or task as it is perceived by the individual who performs it. Meaning in this context is understood as the extent to which a job "(a) is recognized and/or (b) has some point or purpose" (Ariely, Kamenica, and Prelec 2008, p672). The notion of meaning is highly related to the concept of task significance (cf. Hackman and Oldman 1976) capturing the degree "to which a job provides opportunities to improve the welfare of others" (Grant 2008, p110). Ariely et al. (2008), for example, find in a lab experiment that participants' reservation wage strongly depends on the perceived meaning of the task. In their study, meaning is manipulated by the experimenter either explicitly acknowledging or ignoring a participant's performance. In case performance is acknowledged, participants are

\footnotetext{
${ }^{1}$ The literature is too large to be cited in its entirety. As a starting point, see, for example, Deci, Koestner, and Ryan (1999), Bénabou and Tirole (2003), Prendergast (2008) on intrinsic motivation; Ellingsen and Johannesson (2007), Kosfeld and Neckermann (2011), Ashraf, Bandiera, and Lee (2013), Gubler, Larkin, and Pierce (2013) on employee recognition; Blanes i Vidal and Nossol (2011), Barankay (2012), Charness, Masclet, and Villeval (2013) on rank incentives; Francois (2000), Besley and Ghatak (2005), Carpenter and Gong (2013), Gerhards (2013), Fehrler and Kosfeld (2014) on mission motivation; Bénabou and Tirole (2006), Ariely, Bracha, and Meier (2009), Carpenter and Myers (2010) on image motivation; and Akerlof and Kranton (2000, 2005), Chen and Li (2009), Masella, Meier, and Zahn (2012) on group identity.
} 
willing to do the same task for an about 40 percent lower reservation wage compared to if performance is ignored. ${ }^{2}$ Similarly, Grant (2008) documents a significant increase in the performance of fundraising callers when the latter receive positive information about the meaning of their job - in this case, the impact the funds they raise have on others. The interpretation of both findings is that individuals care about "what they do" and respond to changes in perceived job meaning in both labor supply and effort provision.

While the results are intuitive, an open question is how the effect of meaning relates to - and interacts with - the impact of other important motivators, such as monetary incentives and worker recognition. Monetary incentives are the primary and ubiquitous mean of motivating and compensating employees; most economic research on incentives also focuses on financial rewards (Prendergast 1999). In addition, recent evidence shows that recognition, e.g., via symbolic awards such as "Employee of the Month", also plays an important role in labor relationships (Kosfeld and Neckermann 2011, Ashraf et al. 2013, Gubler et al. 2013, Bradler et al. 2013). In order to gain a better and broader understanding of the role of meaning, it seems relevant to assess the influence of meaning on work effort not only in isolation but together and in comparison with these other two important types of incentives.

Further, it is unclear what mechanisms are responsible for the positive effects of meaning, i.e., why individuals care about what they do and what impact their work has on others. One possible mechanism is that individuals care about the different outcomes of their job per se. Another mechanism is that individuals do not care about outcomes directly but are more concerned about their social- and self-image that is associated with their job and its outcomes (Bénabou and Tirole 2006). ${ }^{3}$ Understanding the mechanisms is obviously important in order to integrate

${ }^{2}$ Cf. Chandler and Kapelner (2013) for a similar study on Amazon's MTurk comparing the effect of meaning on participation and effort across different cultures (India and US).

${ }^{3}$ While Grant (2008) suggests that the first mechanism is in place, the results in Ariely et al. (2008) seem more in line with the second mechanism. 
the role of meaning in current behavioral economic models and to derive relevant policy implications for firm owners and managers.

This paper uses a field experiment to analyze the effect of the meaning of a job on workers' performance. Our main research questions are whether meaning affects performance and if so, how the effect of meaning compares to and interacts with the effect of (i) monetary incentives (piece rates) and (ii) worker recognition (symbolic awards). By looking at interactions we are able not only to shed light on the boundaries and contexts in which meaning matters, but also, and perhaps even more importantly, on how and why meaning affects performance. In addition, our study also allows us to address the effectiveness and stability of monetary and non-monetary rewards across different contexts (here, with and without meaning). ${ }^{4}$

In our field experiment, in which we collaborate with a large research center in Hangzhou, China, 413 students are hired for a one-time data entry job. Based on a $2 \times 3$ design, we vary both the meaning of the task and the provision of incentives independently. In the high-meaning condition, workers are told that the data is needed for an important project. In the low-meaning condition, workers receive the information that the data has already been entered and is being analyzed. The demeanor of the research assistant further suggests that their work is of no relevance. Independently of this, workers are either paid a fixed wage (baseline), a fixed wage plus piece rate (monetary incentive), or a fixed wage with the hardest working individual additionally receiving a symbolic award at the end of the session (recognition).

Our main results show that, in line with previous evidence, meaning significantly increases performance. The average effect size is about 14 percent. The effect is significantly larger than the effect of monetary incentives (8 percent) and somewhat smaller than the effect of recognition (19 percent) in the low-meaning condition.

\footnotetext{
${ }^{4}$ To date, only few studies have addressed the robustness of incentive effects across different environments in a comparable way. Exceptions include Camerer and Hoghart (1999) and Stajkovic and Luthans (2001).
} 
We find no significant interaction effect of meaning and monetary incentives, i.e., both motivators have similarly positive effects independent of whether the other incentive is present or not. In particular, we observe no "crowding out" due to monetary incentives in our data, a result that is line with recent evidence from Ariely et al. (2009), who document that monetary incentives increase performance in a task that is (or is not) intrinsically motivated as long as effort is exerted in private. However, we do find a strong and negative interaction effect of meaning and recognition. Recognition substantially increases performance only if workers' perceived meaning of the task is low. Performance in this treatment is as high as in the baseline condition with high meaning, suggesting that recognition provides meaning to an otherwise meaningless task. Recognition has no further effect when workers' perceived meaning is high. Similarly, meaning does not increase performance in the presence of recognition. We can rule out that the ineffectiveness of these rewards is driven by pure ceiling effects, as performance under high meaning and monetary incentives is substantially higher than under high meaning but without incentives.

Overall, our results corroborate the importance of meaning with regard to work effort. Knowing that you matter, matters! They also show that in connection with different levels of meaning, monetary incentives are strong and reliable motivators, while recognition may or may not yield positive effects. Finally, the interactions observed in our data allow us to draw first conclusions about the underling mechanism through which both meaning and recognition affect performance. Our results are inconsistent with the assumption that meaning and recognition influence workers' motivation independently via separate channels. Rather, they suggest that both motivators rely on the same channel, namely image seeking. To see this, note that the model of Bénabou and Tirole (2006) predicts that tasks or rewards with a bearing on an individual's social or self-image work less well in the presence of other motivators that also have image value. The intuition is that the marginal benefit of image rewards declines as motivation is more and more ascribed to image motivation. In consequence, image rewards have substitutive, rather than additive effects, 
which is exactly what we find. Thus, knowing that you matter, matters; however, not because you care directly, but because the image value of what you do increases.

The paper proceeds as follows. Section 2 explains the design and treatments of our field experiment. Section 3 derives behavioral hypotheses. Section 4 presents the results. Finally, Section 5 concludes.

\section{Experimental Design}

\subsection{Basic Set-Up}

In collaboration with the Social Survey Research Center of Zhejiang University in Hangzhou, China, we conducted a field experiment to assess the impact of meaning on work performance in relation to and in combination with monetary incentives and worker recognition. The experiment took place between November 2010 and March 2011. At that time, the research center had just received more than 400 surveys from a large-scale study on the parent-child relationship of migrant workers in China that needed to be filed into an electronic database. In the name of the research center, we hired students for a one-time, two-hours data entry job where they could earn a fixed pay of Yuan $50(\$ 8) .{ }^{5}$ The job offer was announced on the research center's website and posted on campus bulletin boards. Students registered for the job via email.

Upon arrival, students were seated in front of different workstations. The workstations were arranged with sufficient space between them to ensure that individuals felt unobserved. In each session, students received a short introduction about the research center and the particular project the survey was about. Additionally, a short instruction was given on how answers from the surveys were to be filed into the database. During the introduction it was emphasized that the job was one-time, that a second participation was not possible, and that the research center had no job vacancies to fill at the moment. Students used a web interface to file the surveys.

\footnotetext{
${ }^{5}$ The hourly wage for a student job at Zhejiang University ranges between Yuan 20-30.
} 
The web interface was set up like an online version of the survey the students had in front of them. Each survey consisted of 151 questions, 14 of which were free-text fields. The remaining questions were multiple-choice questions.

Every student received 20 to 30 questionnaires that were stacked in a nontransparent box in front of them, with a second box next to it to deposit the completed questionnaires. This reduces peer effects to a minimum as it inhibits students to compare their work with each other (cf. Falk and Ichino 2006, Mas and Moretti 2009). No student completed all the surveys provided to them. When students started working, the research assistant left the room informing students that she was working outside, was available for queries at any time, and that students could take breaks whenever necessary. Five minutes before the end of a session, the research assistant came back into the room asking students to stop working and to close the database. Subsequently, students were asked to fill out a short questionnaire to provide feedback to the research center regarding the job. The questionnaire included questions about satisfaction with the job and the fixed wage, the quantity and quality of the work accomplished, whether full concentration had been required, and whether students had prior experience with entering data.

During work, students could use the internet whenever they wanted, for example to check emails. Together with the fixed wage, these measures (visible internet access and absence of a supervisor in the room) were taken to give students in the baseline condition a certain leeway in how much time to spend on filing the surveys. Furthermore, a collective break was avoided to minimize group effects and communication between participants. Overall, the task was quite exhausting and monotonous. Therefore, we do not believe that students had a lot of intrinsic motivation to perform the task in the absence of any meaning.

\subsection{Treatments}

We implemented a $2 \times 3$ design, in which both the meaning of the task (low meaning vs. high meaning) and the provision of incentives (baseline vs. monetary incentive 
vs. recognition) were varied independently. A detailed script of each treatment condition is given in the Appendix.

First, in the high-meaning condition, students were informed that they contribute to an important research project for which the data needs to be entered, so that the researchers can start with their analysis. In contrast, in the low-meaning condition, students were told that the data had already been entered and that the researchers are analyzing the data; however, one researcher thinks that the data should be entered again. The demeanor of the research assistant in this condition made clear that she did not think that this made any sense and that she had doubts whether the data would ever be used.

Second, with regard to incentives, we implemented as baseline a no-incentive condition, in which students earned only the fixed wage of Yuan 50 independent of work output. Next, in the monetary-incentive condition students earned the fixed wage of Yuan 50 plus a piece rate of Yuan 1 per survey. Finally, in the recognition condition, students earned the fixed wage of Yuan 50 and they were told that the person who entered most data in their workgroup was awarded a smiley button at the end of the work session. The award was handed over by the research assistant in front of all students at the end of the session. The motivation for this treatment manipulation comes from popular awards such as "Employee of the Month", in which top performers' effort is symbolically recognized in a publicly observable manner.

Altogether, our experiment comprises six different treatment conditions. In total, 413 students participated in the study; 213 students participated in the low-meaning condition (baseline 86, monetary incentives 67, recognition 47); 200 participated in the high-meaning condition (baseline 59, monetary incentives 53, recognition 101). ${ }^{6}$

\footnotetext{
${ }^{6}$ Unfortunately, due to bad luck and a mistake in communication, some treatments ended up having more sessions than other treatments. These differences are, however, unsystematic. There are also some differences with respect to the exact number of participants within sessions. We control for groupsize in the empirical analysis. This does not affect the results.
} 


\section{Behavioral Hypotheses}

The main research question of our study is whether the meaning of a task affects performance and if so, how the effect compares to and interacts with the impact of monetary incentives and worker recognition. Informed by previous findings from Ariely et al. (2008) and Grant (2008), we hypothesize that in the absence of any incentives average performance is higher when the perceived meaning of the task is high compared to when the perceived meaning is low.

Hypothesis 1 (Meaning) In the absence of recognition or monetary incentives, average performance is higher in the high-meaning condition compared to the lowmeaning condition.

With regard to the effect of monetary incentives, our null hypothesis is that piece rates increase average performance, because students care about monetary income and have an incentive to increase effort as long as the monetary benefit of Yuan 1 exceeds the marginal cost of completing another survey.

The next question is whether and how the effect of monetary incentives depends on meaning. In recent years a large literature both in psychology and economics has shown that extrinsic incentives such as piece rates may generate important interaction effects with subjects' intrinsic motivation to perform a task, leading to a potential crowding out of behavior (Deci et al. 1999, Gneezy, Meier, and Rey-Biel 2011). As a key channel for these effects an individual's concern for his reputation, or image, vis-à-vis himself and others has been identified (Bénabou and Tirole 2006). ${ }^{7}$

Based on these results, it is possible that monetary incentives may crowd out behavior in our experiment. This holds in particular for the high-meaning condition, where students' intrinsic motivation is expected to be high relative to the lowmeaning condition (cf. Hypothesis 1). However, students always work in private and their performance is never revealed to others, neither in the monetary-incentive

\footnotetext{
${ }^{7}$ See also Gneezy et al. (2011) and Bowles and Polanía-Reyes (2012) for a more general discussion.
} 
condition nor in any other condition. Any image effect can therefore only be due to changes in an individual's self-image. Ariely et al. (2009) show that under such conditions monetary incentives actually do not crowd out behavior, while they do generate negative effects if behavior is made public (and thus social image concerns come into play). This suggests that self-image concerns have less motivational power than similar concerns about one's social-image. ${ }^{8}$ We therefore expect crowding-out effects in our experiment, if they exist, to be small.

Hypothesis 2 (Monetary Incentives) Monetary incentives increase average performance in both meaning conditions; because performance is private, crowdingout effects are expected to be small.

When it comes to worker recognition, our point of comparison is Kosfeld and Neckermann (2011), who show that symbolic awards with little or no material value significantly increase worker performance. The suggested channel for the positive effect is the non-material benefit for the receiver of an award in form of recognition and status both from peers and the award-giving institution. Based on these results, we expect a positive effect of the symbolic award on average performance also in our setting.

The interaction effect with regard to meaning is less clear. On the one hand, it is conceivable that meaning increases the award's value, in so far as receiving an award for a meaningful task may be associated with a higher status and recognition than receiving an award for a relatively meaningless task. In this case, meaning should interact positively with recognition. On the other hand, meaning may also have a recognition element itself, as well. Ariely et al. (2008) argue that behavior is perceived as meaningful if it is acknowledged by others, e.g., the employer, the experimenter, or other people in general. Acknowledgment may be explicit, implicit, or even internalized as is the case, for example, if the behavior is obviously deemed

\footnotetext{
${ }^{8}$ This conclusion is also corroborated by recent evidence from van der Weele and von Siemens (2013).
} 
desirable. This suggests that meaning and recognition may operate, at least partly, via the same channel. If this is so, image-reward theory (Bénabou and Tirole 2006) implies that the interaction effect of meaning and recognition is, in fact, negative. The reason is that the marginal benefit of image rewards declines as image rewards increase, because behavior is more and more ascribed to image motivation (Proposition 4, Bénabou and Tirole 2006). In our setting this means that recognition is expected to work less well when the perceived meaning of the task is high compared to when the perceived meaning is low.

Hypothesis 3 (Recognition) Recognition increases average performance. The interaction effect with meaning is ex-ante ambiguous: (a) if meaning increases the value of awards, the effect of awards should be higher in the high-meaning condition; (b) if, however, the meaning of a task has image value itself, symbolic awards work less well in the high-meaning condition.

Note that based on Hypothesis 3 our data allows us to draw first conclusions about the underlying channels through which meaning and recognition operate. A positive (or zero) interaction effect indicates that meaning and recognition enter a person's utility function separately, possibly even reinforcing each other (Hypothesis 3a). In contrast, a negative interaction effect suggests that meaning and recognition operate via the same channel, namely image rewards (Hypothesis 3b). We now turn to the results of our field experiment.

\section{Results}

In the results section we proceed as follows. We first consider the effect of meaning in the absence of either monetary incentives or recognition. We then compare the size of the effect of meaning with the effect size of monetary incentives and recognition, respectively. Finally, we look at interaction effects.

Figure 1 shows average performance in terms of the total number of survey questions entered in our baseline treatment without incentives, in both the low- 


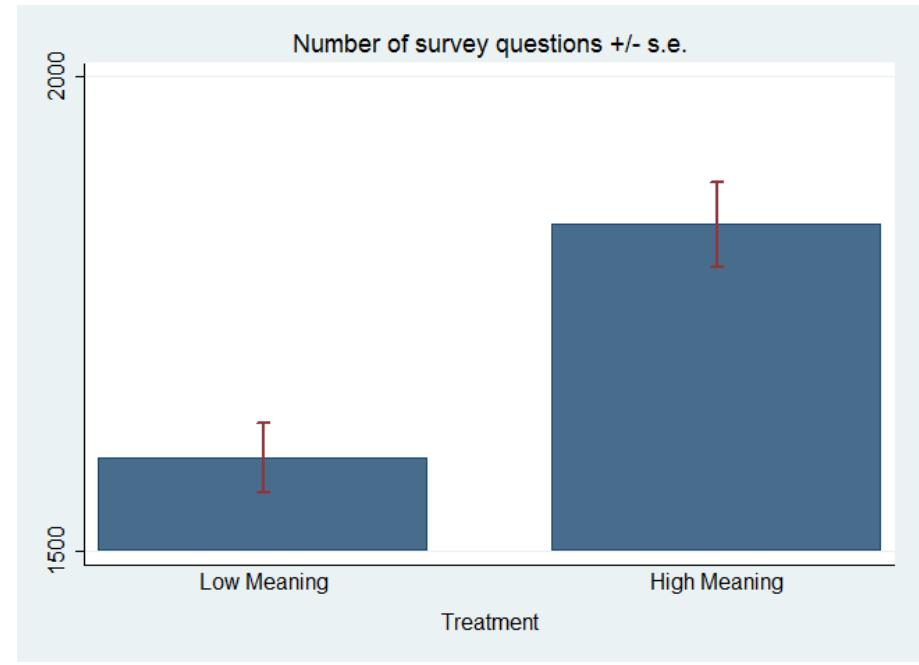

Figure 1: Effect of Meaning in the Absence of Incentives

and the high-meaning condition. The data speak a clear language. Increasing the meaning of the task when agents face no explicit incentives raises performance from 1598 questions in the low-meaning condition to 1844 questions in the highmeaning condition (Mann-Whitney test, $\mathrm{p}=0.000)^{9}$. Thus, we find strong support for Hypothesis 1 corroborating the motivational importance of a worker's perceived meaning of his task with regard to intrinsically motivated effort.

The average effect size of meaning is 15.4 percent (246 questions) based on raw data. If we compare this to the effect of monetary incentives and recognition alone, we find that meaning has a significantly larger effect than monetary incentives but the effect is similar to, and not significantly different from, the effect of recognition. Consider Table 1, which shows the absolute and relative increase in performance in our three main treatment manipulations based on raw data, taking the low-meaning/baseline condition as a benchmark. On average, monetary incentives increase performance by 138 questions or 8.6 percent (Mann-Whitney test, $\mathrm{p}=$ 0.008). This is significantly less than the effect of meaning (Mann-Whitney test, $\mathrm{p}=$

\footnotetext{
${ }^{9}$ Unless otherwise specified, all tests are two-sided.
} 
0.049). In comparison, recognition increases performance even by 291 questions, or 18.2 percent, (Mann-Whitney test, $\mathrm{p}=0.000$ ); however, the differential effect compared to meaning is not statistically significant (Mann-Whitney test, $\mathrm{p}=0.809$ ). Overall, the data suggest that meaning and recognition have similarly strong effects while the effect of monetary incentives is positive but relatively weaker.

Table 1: Effect of Meaning vs. Monetary Incentives vs. Recognition

\begin{tabular}{lccc}
\hline \hline & High Meaning & Monetary Incentives & Recognition \\
\hline Average Performance Increase & 246 & 138 & 291 \\
Percentage & $15.4 \%$ & $8.6 \%$ & $18.2 \%$ \\
\hline
\end{tabular}

Note: Performance is measured as the number of survey questions entered into the database within the 115 minutes work time. Effects are based on raw data with the low-meaning/baseline condition as the benchmark.

Let us now turn to the interaction effects. Figure 2 shows average performance in all six treatments. The left panel compares students' performance with and without monetary incentives in both meaning conditions; the right panel shows the same comparison for recognition.

Two important observations can be made from Figure 2. First, monetary incentives increase performance both when meaning is low (black dashed line) and when meaning is high (grey solid line). We have already seen that students enter significantly more questions in the low-meaning condition if they are offered a piece rate compared to if they are paid only a fixed wage. Figure 2 shows that a similar positive effect can be observed when the perceived meaning of the task is high. In this case, average performance increases from 1844 questions under the fixed wage to 1941 questions under piece rates, which constitutes an increase of about 5 percent based on raw data (Mann-Whitney test, $\mathrm{p}=0.140$ ). Second, recognition increases performance only when the perceived meaning of the task is low. Again, we have seen above that performance in the low-meaning condition increases by about 18 

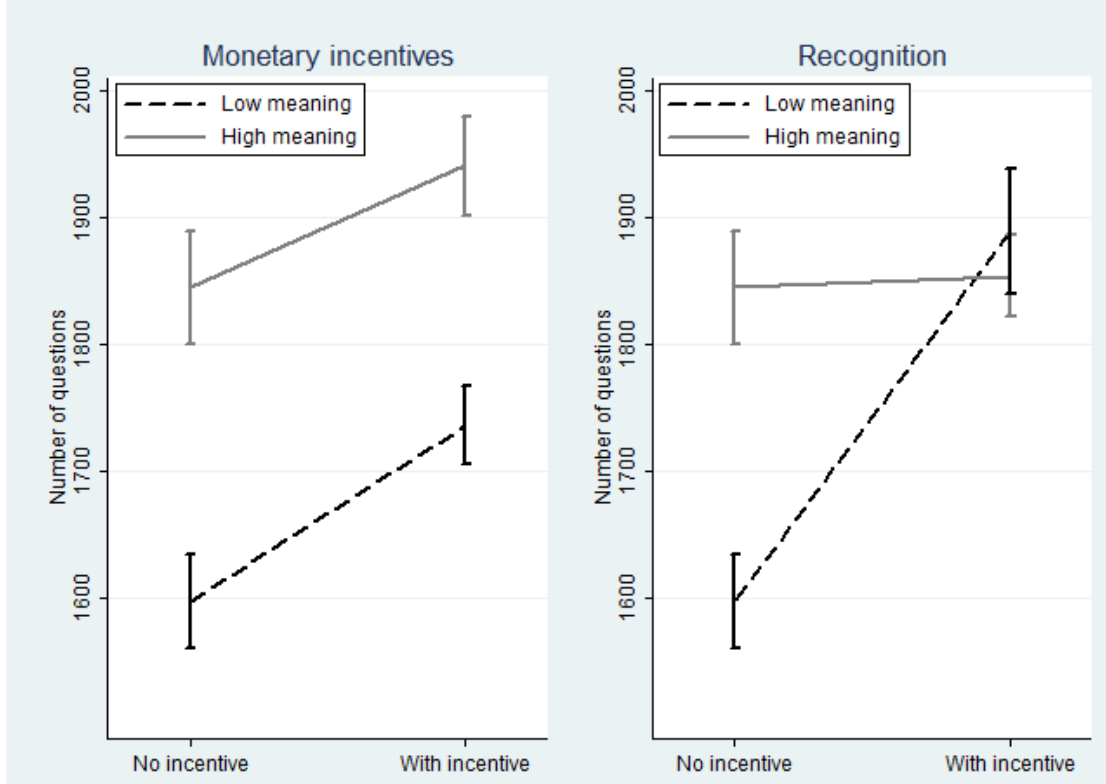

Figure 2: Effect of Monetary Incentives and Recognition Conditional on Meaning

percent if students are recognized by a symbolic award. In contrast, if the meaning of the task is high, the introduction of a symbolic award has no sizable effect on performance. Students' average performance in this case is 1853 with award and 1844 without award, which is not statistically different (Mann-Whitney test, $\mathrm{p}=$ $0.989)$.

The above findings are confirmed by a regression analysis with individual performance as the dependent variable. Table 2 displays the results. The omitted category is the low-meaning condition without incentives. We include dummies for the high-meaning condition, the provision of monetary incentives and recognition, as well as for the interaction between the two incentives schemes and the high-meaning condition, respectively. The first column includes no controls, columns II and III add controls for group size and gender, as well as for answers to the feedback form students filled out at the end of the job. Comparing the three columns in Table 2 shows that adding control variables has no notable effect on our results. 
Table 2: Treatment Effects on Performance

\begin{tabular}{lccc}
\hline \hline & I & II & III \\
\hline High meaning & $247.238^{* * *}$ & $241.262^{* * *}$ & $231.043^{* * *}$ \\
Monetary incentive & $(70.367)$ & $(69.691)$ & $(68.232)$ \\
& $138.397^{* *}$ & $143.698^{* * *}$ & $150.555^{* * *}$ \\
Recognition & $(52.518)$ & $(52.409)$ & $(52.074)$ \\
& $290.995^{* * *}$ & $314.093^{* * *}$ & $308.254^{* * *}$ \\
High meaning $\times$ Monetary incentive & $(63.931)$ & $(71.395)$ & $(61.394)$ \\
High Meaning $\times$ Recognition & -42.590 & -50.226 & -23.098 \\
Constant & $(79.549)$ & $(78.531)$ & $(82.372)$ \\
& $-282.267^{* * *}$ & $-293.532^{* * *}$ & $-275.482^{* * *}$ \\
Controls (group size, gender) & $(93.021)$ & $(95.093)$ & $(85.259)$ \\
Controls (questionnaire) & $1597.558^{* * *}$ & $1308.645^{* * *}$ & $1246.688^{* * *}$ \\
\hline Observations & $(49.090)$ & $(188.703)$ & $(187.663)$ \\
Sessions & No & Yes & Yes \\
Adj. $R^{2}$ & No & No & Yes \\
\hline Note: & 413 & 413 & 410 \\
Nhe & 5.110 & 0.114 & 0.150 \\
\hline
\end{tabular}

Note: The table reports OLS estimates of treatments on performance. Performance is measured as the number of survey questions entered into the database within the 115 minutes work time. Standard errors in parentheses account for clustering at the session level. The omitted category is the low-meaning/baseline condition. Asterisks next to coefficients indicate significance at the 10/5/1 percent level. Column I contains no controls. Column II contains controls for group size and gender. Group size is the number of students who worked together in a group. Column III adds answers to the questionnaire (whether the individual was happy with the job, with the fixed wage, the quantity of work accomplished, the quality of work accomplished, whether full concentration had been required to complete the job, and whether the individual had prior experience with entering data). 
Taking the full model in column III as a benchmark, we see that all treatments elicit substantial and statistically significant performance increases over the baseline condition. In particular, increasing only the perceived meaning of the task raises performance by about 230 survey questions on average compared to performance in the situation with low meaning and no additional incentives. In comparison, paying a piece rate increases average performance by 150 questions. The difference between these two effects is statistically significant $(\mathrm{p}=0.004)$. Paying a piece rate has a similarly positive effect if the perceived meaning of the task is high. In this case, average performance increases by 127 questions, which is less than in the low-meaning condition, but the differential effect is not statistically significant as the interaction between high-meaning and monetary incentives shows. By the same token, increasing meaning in the presence of monetary incentives also increases performance. The average effect size is 208 questions. Overall, the results confirm our first two Hypotheses 1 and 2: Meaning and monetary incentives are both significant motivators and there are no observable crowding-out effects.

Result 1 (Meaning) Increasing the meaning of a task significantly raises performance in the absence of incentives. The estimated effect size is 14 percent.

Result 2 (Monetary Incentives) Monetary incentives increase performance both when meaning is low and when meaning is high. The estimated effect size ranges between 7 and 9 percent. Crowding-out effects are small and insignificant.

By far the largest effect comes from symbolic awards, i.e., worker recognition. In the low-meaning condition, average performance increases by more than 300 question when a symbolic award is offered. Taking controls into account, we see that this effect is significantly stronger than the effect of monetary incentives $(p=0.002)$ but not significantly different from meaning alone $(\mathrm{p}=0.249)$. In contrast, if meaning is high, the effect of recognition is basically zero. Average performance with symbolic award is about 33 questions higher than without, which is not statistically different, 
and the interaction effect between meaning and symbolic incentives is negative and highly significant.

In much the same way as recognition does not increase average performance when meaning is high, an increase in meaning has no effect in the presence of recognition, either. Column III in Table 2 suggests that performance is actually reduced by about 40 questions but the difference is not statistically significant $(\mathrm{p}=0.415)$. We summarize these findings in Result 3.

Result 3 (Recognition) The effect of worker recognition strongly depends on meaning. If meaning is low, recognition increases performance by about 19 percent. If meaning is high, however, recognition has no observable effect.

Result 3 suggests that meaning and recognition entail substitutive effects as is indicated by the negative interaction of the two variables. This speaks against the idea that both motivators operate separately from each other and enter an individual's utility function via different, possibly additive, channels. Rather, the observation is in line with image-reward theory in the spirit of Bénabou and Tirole (2006). The theory predicts that incentive effects of image rewards, while positive, are inherently limited due to the declining marginal benefit of these rewards. Assuming that meaning and recognition both have image value, i.e., operate via the same channel, this is exactly what we find. In sum, our data reject Hypothesis 3a and confirm Hypothesis 3b.

Finally, we checked for gender effects and do not find any. We also find no systematic differences with respect to the number of mistakes students make across treatments, which is probably due to the fact that the number of mistakes in our set-up is in general extremely low: $2 / 3$ of the students have an error rate of less than 1 percent and 97 percent have an error rate of less than 5 percent. 


\section{Conclusion}

This paper studies the impact of perceived meaning on work performance. The objective is threefold: (i) to analyze the direct effect of meaning on performance, (ii) to compare the effect of meaning to the effect of important other motivators such as monetary incentives and worker recognition, and (iii) to investigate the interactions between the different types of incentives.

Our results, which are based on a field experiment in collaboration with the Social Survey Research Center of Zhejiang University, corroborate previous findings on the importance of meaning for worker's willingness to exert effort (Ariely et al. 2008, Grant 2008). The results confirm that providing workers with a heightened awareness of the meaning of their job is a powerful tool to increase performance. In the setting of this study, meaning clearly outperforms monetary incentives and works almost equally well as worker recognition in the absence of meaning. This has important and far-reaching implications for the workplace, suggesting that it might be more cost-effective for managers to actually talk to workers and spend time on the factory floor communicating the value of their work than to institute complex compensation schemes to incentivize performance.

Nevertheless, we also find that monetary incentives do increase performance in a statistically and economically significant way. Hence, even though, non-monetary rewards may be more cost-effective at times, monetary incentives work well and are also very robust to different contexts (here in situations with high and low perceived task meaning). The fact that we do not observe a crowding-out effect in our data is in line with recent evidence from Ariely et al. (2009), who also find that monetary incentives do not reduce performance in image-motivated tasks as long as effort is exerted in private.

The finding that worker recognition in form of symbolic awards matches the impact of meaning and that the combination of meaning and recognition together does not lead to higher performance than either in isolation, suggest that both meaning and recognition act as image rewards with substitutive effects on performance. 
This insight has major repercussions for behavioral theories of worker motivation as well as practical workplace management. With respect to the underlying preference structure it implies that increasing the meaning of a task and providing worker recognition (via symbolic awards) do not affect worker's motivation and utility separately. Rather, our results suggest that meaning and recognition operate via the same channel, namely image rewards (Bénabou and Tirole 2006).

Our study presents a first step in understanding relative effect sizes of monetary and non-monetary rewards as well as important context dimensions (like meaning). Moreover, the interactions we included in our design allow us to draw first conclusions about the underlying preference structure. Still, there is room for improvement. Future research needs to look at further incentives and contexts and their interactions as well as test the robustness of the current set of findings over time and across different settings. 


\section{References}

Akerlof, George A. and Rachel E. Kranton. 2000. "Economics and Identity," The Quarterly Journal of Economics, 115(3): 715-753.

Akerlof, George A. and Rachel E. Kranton. 2005. "Identity and the Economics of Organizations," Journal of Economic Perspectives, 19(1): 9-32.

Ariely, Dan, Anat Bracha, and Stephan Meier. 2009. "Doing Good or Doing Well? Image Motivation and Monetary Incentives in Behaving Prosocially," American Economic Review, 99(1): 544-555.

Ariely, Dan, Emir Kamenica, and Drazan Prelec. 2008. "Man's Search for Meaning: The Case of Legos," Journal of Economic Behavior E Organization, 67: $671-677$.

Ashraf, Nava, Oriana Bandiera, and Scott S. Lee. 2013. "Awards Unbundled: Evidence from a Natural Field Experiment," Journal of Economic Behavior $\& 5$ Organization, forthcoming.

Barankay, Iwan. 2012. "Rank Incentives: Evidence from a Randomized Workplace Experiment, mimeo.

Bénabou, Roland and Jean Tirole. 2003. "Intrinsic and Extrinsic Motivation," Review of Economic Studies, 70: 489-520.

Bénabou, Roland and Jean Tirole. 2006. "Incentives and Prosocial Behavior," American Economic Review, 96(5): 1652-1678.

Besley, Timothy and Maitreesh Ghatak. 2005. "Competition and Incentives with Motivated Agents," American Economic Review, 95(3): 616-636.

Blanes i Vidal, Jordi and Mareike Nossol. 2011. "Tournaments Without Prizes: Evidence from Personnel Records," Management Science, 57(10), 17211736 . 
Bowles, Sam and S. Polonía-Reyes. 2012. "Economic Incentives and Social Preferences: Substitutes or Complements?," Journal of Economic Literature, $50,368-425$.

Bradler, Christiane, Robert Dur, Susanne Neckermann, and Arjan Non. 2013. "Employee Recognition and Performance: A Field Experiment," TI Discussion Paper, 038.

Camerer, Colin F. and Robin M. Hogarth. 1999. "The Effects of Financial Incentives in Experiments: A Review and Capital-Labor-Production Framework," Journal of Risk and Uncertainty, 19 (1-3), 7-42.

Carpenter, Jeffrey and Caitlin Knowles Myers. 2010. "Why Volunteer? Evidence on the Role of Altruism, Image, and Incentives," Journal of Public Economics, 94 (11-12), 911-920.

Carpenter, Jeffrey and Erick Gong. 2013. "Motivating Agents: How Much Does the Mission Matter?," IZA Discussion Paper, No. 7602.

Chandler, Dana and Adam Kapelner. 2013. "Breaking Monotony with Meaning: Motivation in Crowdsourcing Markets," Journal of Economic Behavior Ef Organization, 90: 123-133.

Charness, Gary, David Masclet, and Marie Claire Villeval. 2013. "The Dark Side of Competition for Status," Management Science, forthcoming.

Chen, Yan, and Sherry Xin Li. 2009. "Group Identity and Social Preferences," American Economic Review, 99(1), 431-457.

Deci, Edward L., R. Koestner, and Richard M. Ryan. 1999. "A Metaanalytic Review of Experiments Examining the Effects of Extrinsic Rewards on Intrinsic Motivation," Psychol Bulletin, 125 (6), 692-700.

Ellingsen, Tore and Magnus Johannesson. 2007. "Paying Respect," Journal of Economic Perspectives, 21(4): 135-150. 
Falk, Armin and Andrea Ichino. 2006. "Clean Evidence on Peer Effects," Journal of Labor Economics, 24(1): 39-58.

Fehrler, Sebastian and Michael Kosfeld. 2007. "Pro-Social Missions and Worker Motivation: An Experimental Study," Journal of Economic Behavior $\&$ Organization, forthcoming.

Francios, Patrick. 2000. "Public Service Motivation as an Argument for Government Provision," Journal of Public Economics, 78: 277-299.

Gerhards, Leonie. 2013. "Incentives for Motivated Agents: An Experiment with Employees from a Non-profit Organization," mimeo.

Gneezy, Uri, Stephan Meier, and Pedro Rey-Biel. 2011. "When and Why Incentives (Don’t) Work to Modify Behavior," Journal of Economic Perspectives, 25(4): 191-2010.

Grant, Adam. 2008. "The Significance of Task Significance: Job Performance Effects, Relational Mechanisms, and Boundary Conditions," Journal of Applied Psychology, 93(1): 108-124.

Gubler, Timothy, Ian Larkin, and Lamar Pierce. 2013. "The Dirty Laundry of Employee Award Programs: Evidence from the Field," Harvard Business School Working Paper, 13-069.

Hackman, J. Richard and Greg R. Oldham. 1976. "Motivation Through the Design of Work: Test of a Theory," Organizational Behavior and Human Performance, 16: 250-279.

Kosfeld, Michael and Susanne Neckermann. 2011. "Getting More Work for Nothing? Symbolic Awards and Worker Performance," American Economic Journal: Microeconomics, 3(3): 86-99.

Mas, Alexandre and Enrico Moretti. 2009. "Peers at Work," American Economic Review, 99(1): 112-145. 
Masella, Paolo, Stephan Meier, and Philipp Zahn. 2012. "Incentives and Group Identity," mimeo.

Prendergast, Canice. 2008. "Intrinsic Motivation and Incentives," American Economic Review, 98(2): 201-205.

Prendergast, Canice. 1999. "The Provision of Incentives in Firms," Journal of Economic Literature, 37(1): 7-63.

Stajkovic, Alexander D. and Fred Luthans. 2001. "Differential Effects of Incentive Motivators on Work Performance," Academy of Management Journal, 44(3): 580-590.

van der Weele, Joel, and Ferdinand von Siemens. 2013. "Bracelets of Pride and Guilt? An Experimental Test of Self-Signaling in Charitable Giving," CESifo Working Paper, No. 4674 


\section{Appendix: Instructions (English translation)}

"Good morning, I am X, a graduate assistant of the Social Sciences Research Center, and I'm in charge of today's data entry work. The computers have been turned on for you, please sit down wherever you like.

Zhejiang University Social Sciences Research Center belongs to the Institution of Social Sciences. The Center's task is the investigation of social, economic and other issues. The subject of the present survey is parent-child relationships of migrant workers from all provinces of China."

\section{High-meaning condition:}

"As we need the results of these surveys as soon as possible, the Center recruited a group of students to help enter the data. Today your job is to enter the results of these surveys into an online database, so that the researchers can start the analysis."

\section{Low-meaning condition:}

'Actually, the data have already been entered, the researchers are analyzing it already. Some other researcher in the survey center insists that the data is entered a second time and he pays for it."

[In addition, the demeanor of the research assistant suggests that she does not think that this makes any sense and that she has doubts whether the data will ever be used.]

"I will now explain to you how to use the system. Everyone should have a piece of paper on the table in front of her or him. Please use the username to log in. After having logged in, you are asked to enter the survey identifier, which you can find on the upper right corner of the survey. This number is very important to us, so please make sure that you enter it correctly. Afterwards, click on "next question", and you'll see an exact replica of the first survey question on your screen. Please enter the answer that the respondent provided on the screen. If a question is not answered, please select "missing". Continue like this until all the answers are 
recorded, and then click "end".

There are two boxes on your desk. The left one contains the surveys we ask you to enter. Please enter them one by one in the original order, and put the recorded surveys in the box to your right. You will work for two hours. There are a lot of surveys in the left box. We do not ask you to complete all of them within the two hours, but please enter as many as possible.

The data you enter is saved into the database that the researchers access. Let me emphasize that your data goes directly to that database, so please make sure that you enter the data correctly.

At the end of the two-hour working period, you will receive 50 Yuan for your work."

\section{Monetary-incentives condition:}

"Besides this, you will get 1 Yuan per survey that you completed in these two hours."

\section{Recognition condition:}

"The system displays at the end who in your group of six has entered the most surveys. As a special thanks, I will tell you who has worked hardest in your group, and give him or her this little gift [show the button] for their hard work in front of all of you."

"Do you have any questions? If not, please start now. I will be working in the adjoining room. If you have questions, please ask me any time."

[Students start working. 5 minutes before the end of the work, the research assistant enters the room.]

"There are now 5 minutes of worktime left, thank you for your work. You can stop now and close the entry system. In the remaining few minutes, please fill out a feedback form. This is the first time that we recruited so many people to enter data. We would therefore like to get your feedback so that we can make the job 
better in the future. The form is very simple, and won't take much time."

\section{Recognition condition:}

"I just checked the system. X (username) has entered the most surveys. Can you please identify yourself? Congratulations to you! This little gift is for you [hand over the button], thank you! Also thank you all for your work."

"When you have finished the feedback form, please come next door to be paid. By the way, please leave the username on your table." 